\title{
Microcontroller Based Maximum Power Point Tracking For Photovoltaic Solar Panel
}

\author{
Museeb M. Jasim \\ University of Mosul \\ College of Electronics Eng. \\ Electronics Dept.
}

\author{
Kamil G. Salih \\ University of Mosul \\ College of Agriculture \& Forestry \\ Basic Science Dept.
}

\author{
Rasha E. Majed \\ University of Mosul \\ College of Electronics Eng. \\ Computer Eng. Dept.
}

\begin{abstract}
Many papers are published in the past and at present time which operate the solar photovoltaic (PV) panel at its maximum power point, by implementing an analogue or digital electronic circuits which are known as maximum power point trackers (MPPT). The main purpose of the researches are to obtain maximum power from the (PV) solar panel under different atmospheric conditions. In this paper a digital technique based on microcontroller type 8051 is used to design and implement the (MPPT) using maximum power point voltage method. The proposed (MPPT) consists of three major units (i) the solar (PV) panel (ii) the DC/DC step down inverter (iii) the control unit and computation of maximum power point based on microcontroller.

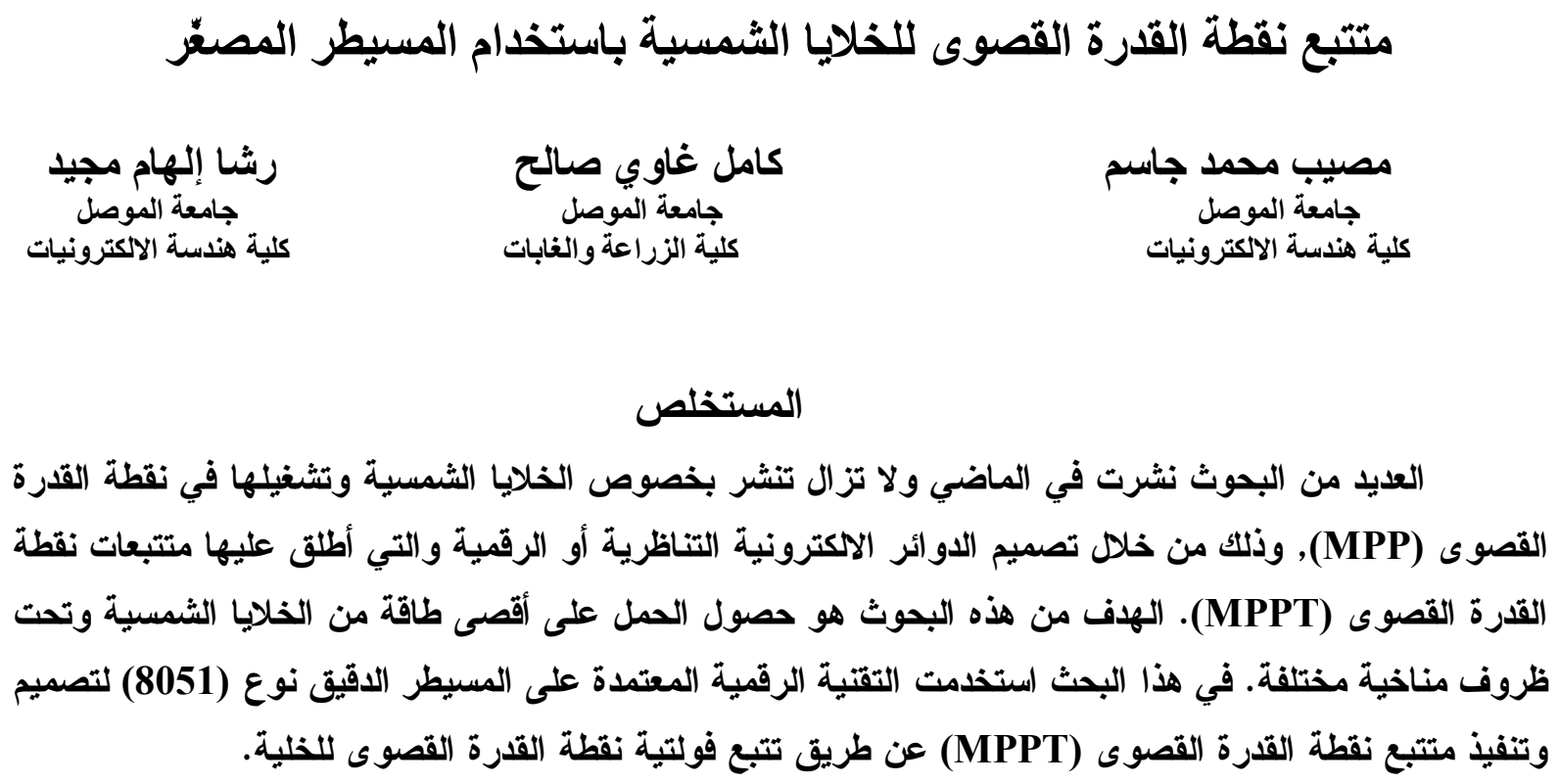

كامل غاوي صالح جامعة الموصل كلية الزراعة والغابات

\section{المستخلص}

العديد من البحوث نشرت في الماضي ولا تزال تنشر بخصوص الخلايا الثمسية وتثغيلها في نقطة القدرة

القصوى (MPP), وذلك من خلال تصميم الدوائر الاكترونية التناظرية أو الرقمية والتي أطلق عليها متتبعات نقطة القدرة القصوى (MPPT). الهدف من هذه البحوث هو حصول الحمل على أقصى طاقة من الخلايا الثمسية وتحت ظروف مناخية مختلفة. في هذا البحث استخدمت التقنية الرقمية المعتمدة على المسيطر الاقيق نوع (8051) لتصميم وتنفيذ متتبع نقطة القدرة القصوى (MPPT) عن طريق تتبع فولتية نقطة القدرة القصوى للخلية. 


\section{Introduction:}

The photovoltaic (PV) solar panels are semiconductor devices which convert the solar illumination power direct to electricity and their operational characteristics depend on incident sun light (insolation) level and the surface temperature that developed on the cell surface as the insolation, ambient temperature and current flow varies[1].

Energy conversion using solar (PV) panels is considered one of the best promising techniques in the field of renewable energy sources since photovoltaic (PV) panels uses free and non exhaustible sunlight as the fuel. Due to pollution and maintenance free (PV) panels are getting increasing worldwide acceptance. (PV) panels where first used as a main power supply for satellites in outer space, later (PV) panels designed as stand-alone systems for applications as power supply for housing systems, storage systems, and long distance places where main electricity can not reach, water pumping, electric vehicles, swimming pool heating systems etc. Stand-alone PV systems are normally equipped with storage batteries to maintain electricity for sunless hours. Grid connected (PV) systems that back up or supplement the grid power are also becoming popular[2].

But facing all benefits of (PV) panels as a source of electrical energy in photovoltaic systems, still there are some drawbacks limiting their use at large scale such as low conversion efficiency of the cell and the high initial cost. Beside this and due to the nonlinearity characteristics of the solar cell, (PV) systems need to be tracked at maximum power point ( MPPT ) to obtain maximum power extraction in certain conditions such as sun light, load, and surface temperature[3]. For the above reason an analogue or digital circuit known as maximum power point tracker (MPPT) is developed and interfaced between the (PV) panel and the load as shown in Fig.(1). This circuit forces the system operating point towards the (MPP) under all varying operating conditions.

In general, the (PV) energy conversion systems of medium and large sizes incorporate three possible approaches of maximizing power extraction. These approaches are sun tracking and (MPPT) or both, however, it is only possible/ feasible to implement (MPPT) for small size systems[4].

The $\mathrm{v}$-i characteristics of a (PV) panel is highly non-linear and varies drastically with solar insolation (Light intensity) and the surface temperature. The variations of $\mathrm{v}-\mathrm{i}$ characteristics of a particular (PV) panel with solar insolation and temperature are shown in Figs.(2) and (3) respectively. It can be noticed that (PV) panel gives maximum power $\mathrm{P}_{\max }$ at a particular voltage $V_{m p}$ and current $I_{m p}$ where the power $p=v i$ is maximum at different operational condition of the characteristics curve. For maximum output power, the internal resistance of the (PV) panel becomes equal the load resistance. The DC/DC step down converter normally achieve this purpose.

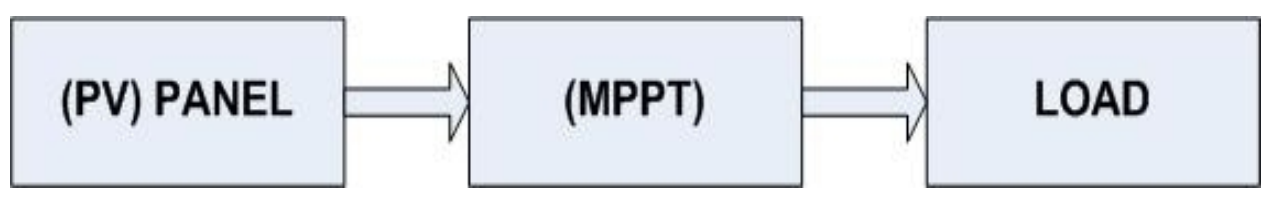

\section{Fig. (1): A typical solar (PV) based system with (MPPT)}




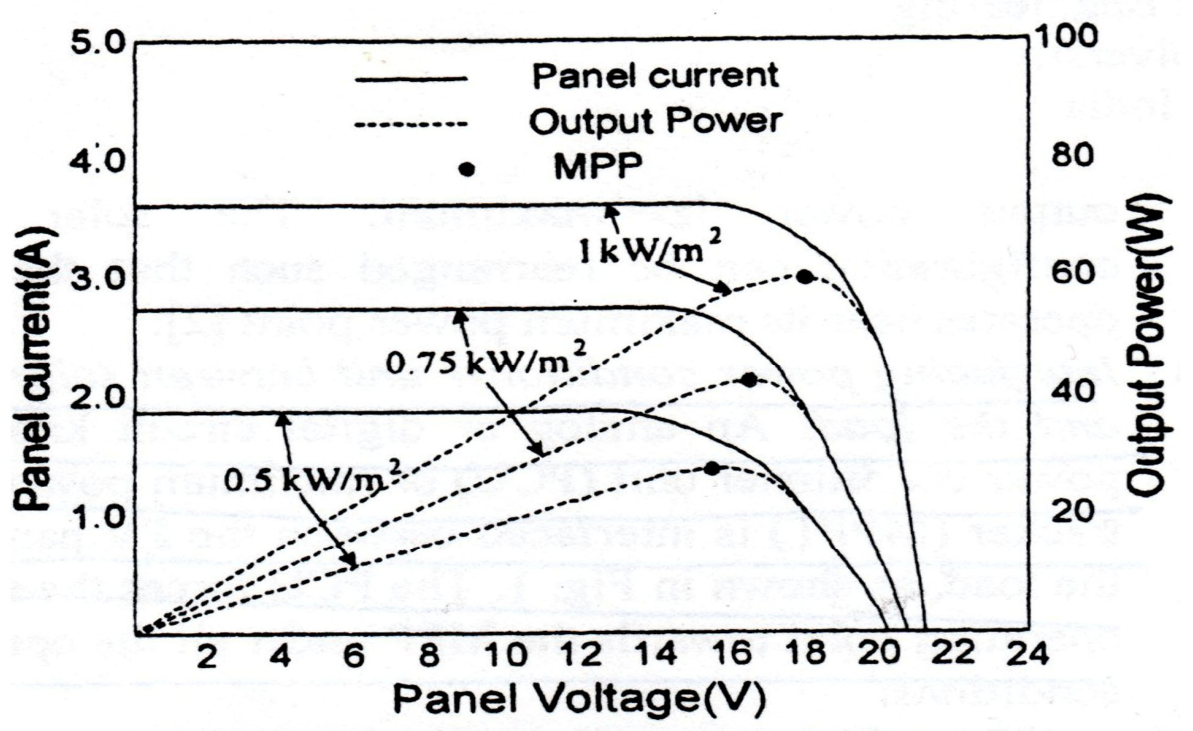

Fig. (2) : Insolation characteristics of a PV panel

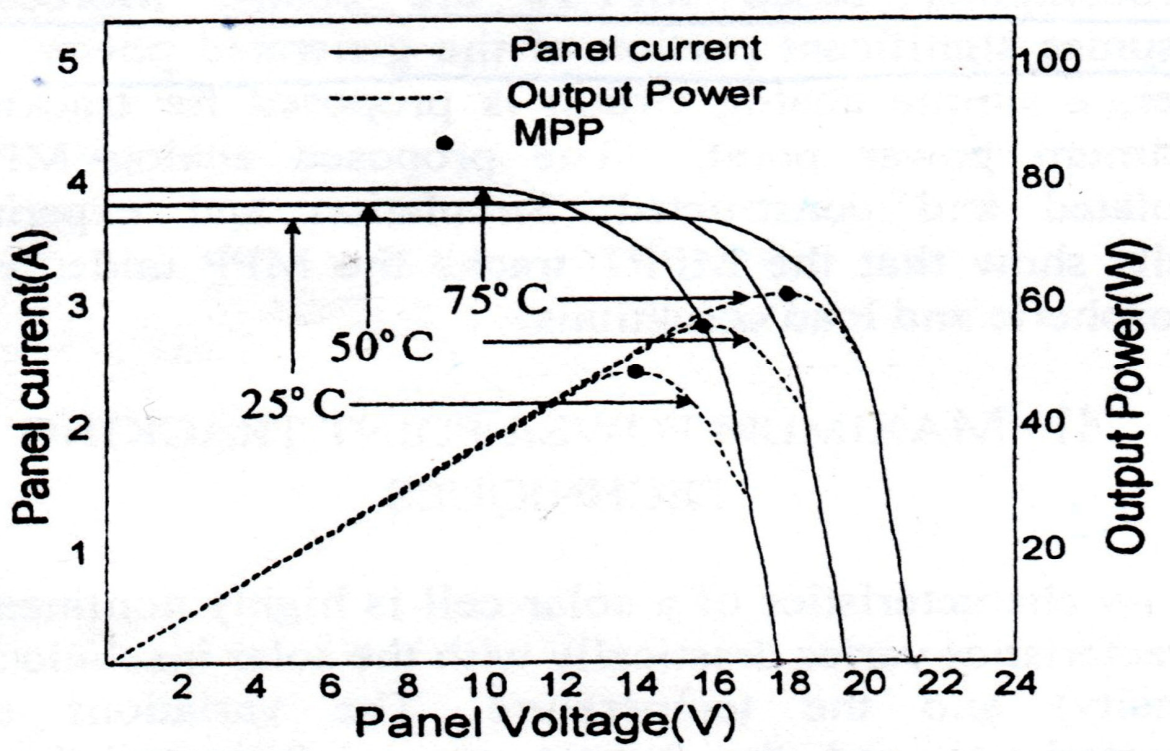

Fig. (3) : Temperature characteristics of a PV panel

\section{Survey Of Maximum Power Point Tracking (MPPT) METHODS:}

Here are various methods of performing (MPPT) on (PV) panel systems to ensure maximum output power at various operational conditions, we state every method with its brief explanation:

1- Constant voltage method: This method was used in a very early (MPPT) where the (PV) panel voltage is compared with a constant reference voltage which considered the MPP voltage at specific ambient conditions, the error signal is used to control the dc-dc converter to maximize the power to the load. This method is simple to implement but it is not accurate $[5]$.

2- Perturb-and-observation (PAO) method: In this method the current pulled from the $(\mathrm{PV})$ panel is perturbed and the resulting power is observed. This is an iterative method 
which perturbs the operation point of the (PV) panel to find the direction of change for maximizing the power output. The main disadvantage of this method is that the operating point is oscillating around the MPP and its slow response in a rapped change of radiation[6][7]. An improve MPPT algorithm for rapid irradiation changes which is called as optimized $d P$-P\&O can slightly improve the traditional method [8].

3- Incremental conductance method: The incremental conductance method basically depends on comparison between the incremental conductance of the (PV) panel and the instantaneous conductance and control the duty cycle of the dc-dc converter according to following formula:

$\mathbf{d} \mathbf{I} / \mathbf{d} \mathbf{V}=-\mathbf{I} / \mathbf{V}$

Where V \& I represents the voltage and current of the (PV) panel respectively. The accuracy is the main advantage of this method but it needs complex circuitry to implement[9].

4- A Takagi-Sugeno fuzzy-model-based approach also implemented in such tracking system but the main disadvantage is that the method need the very specific parameters of each component in the system and the maximum power point is not really achieved [10].

5- Maximum power point voltage method: The basic idea of this method is to derive the voltage of the maximum power $\mathrm{V}_{\mathrm{mp}}$ from the open circuit voltage $\mathrm{V}_{\mathrm{oc}}$ of the (PV) panel, as can be easily shown from fig.(2) \& fig.(3). Due to the change in ambient conditions, $V_{o c}$ changes which cause a change in $\mathrm{V}_{\mathrm{mp}}$. It can be noticed that there exists almost a linear relationship between $\mathrm{V}_{\mathrm{mp}} \& \mathrm{~V}_{\mathrm{oc}}$ :

$\mathbf{V}_{\mathbf{m p}}=\mathbf{M}_{\mathbf{v}} \mathbf{V}_{\mathbf{o c}}$

Where $\mathrm{M}_{\mathrm{v}}$ is called the voltage factor and its value found to be around 0.8 in experimental analysis [11].

In this paper the maximum power point voltage method has been used because $V_{m p}$ can be easily calculated from the periodical measurements of the open circuit voltage of the (PV) panel and multiplying it by the factor (0.8) and storing it in the general purpose register (GPR) area of the data memory of a microcontroller unit. This value is used to compute the controlling duty cycle ( $\left.\mathrm{T}_{\text {on }} \& \mathrm{~T}_{\text {off }}\right)$ of the generated PWM signal by a microcontroller and fed to the DC/DC step down converter so as to achieve maximum power extraction. The maximum power point voltage method is an open loop control for (MPPT)[12]. The microcontroller based algorithm will simplifying greatly the design of the (MPPT) due to its powerful computational instructions set.

\section{Design \& Implementation of (MPPT) Based on 8051 Micro-controller: Reference Signal Unit:}

The Function Generator (F.G.) shown in fig.(4) is used to generate the reference signal $\left(f_{c}\right)$ in the range of $4 \mathrm{KHz}$ to $20 \mathrm{KHz}$. This value is stored in the data memory at address $(21 \mathrm{H})$ and used to compute the duty cycle of PWM by the control program. In this work the reference signal shown in fig. $(5)$ is not connected to any part of the (MPPT) circuit but connected to an oscilloscope for demonstration purposes and shall be clarified later in the experimental results. 


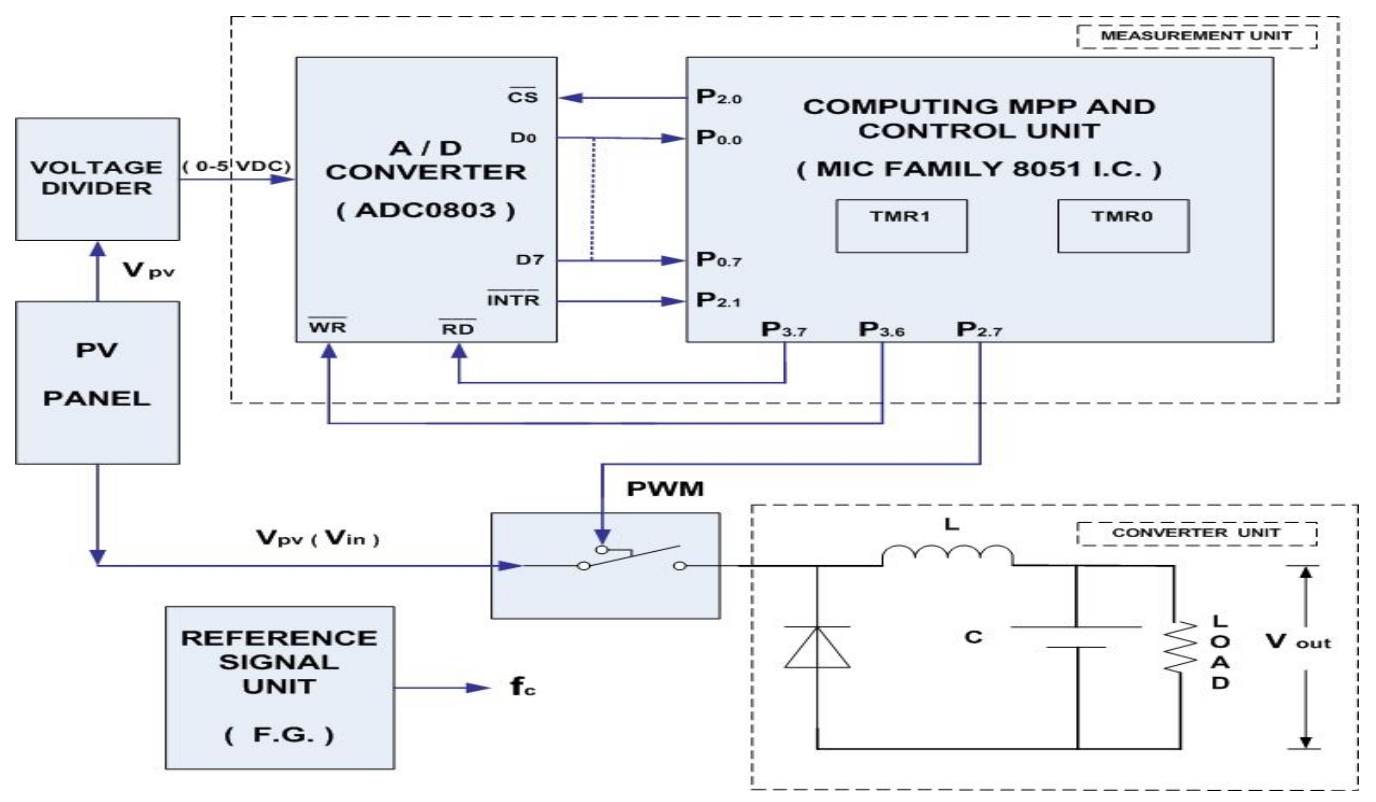

Fig. 4 : Proposed (MPPT) circuit diagram

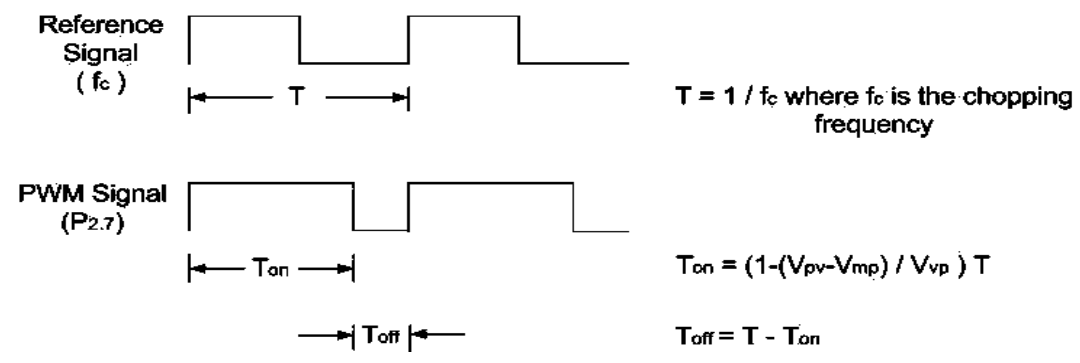

Fig. (5) : Timing diagram of Reference and PWM signals

\section{Computing (MPP) And Control Unit:}

The 8051 microcontroller [13] with its high capability of control using Boolean processor operates on single bits (210 bit-addressable locations), four basic Input/Output ports $\left(\mathrm{P}_{0}\right.$, $\mathrm{P}_{1}, \mathrm{P}_{2}$ and $\mathrm{P}_{3}$ ) and two internal 16-bit timers (TMR0, TMR1) is used as a base unit. In this paper the control bit $\left(\mathrm{P}_{2.0}\right)$ is used to enable the ADC (chip select $\mathrm{CS}$ ), control bit $\left(\mathrm{P}_{3.7}\right)$ used as an output control bit to initiate the start conversion of the ADC, while control bit $\left(\mathrm{P}_{2.1}\right)$ used as status bit (input bit) to test the end of conversion of the ADC (Data Ready). Initiating the read cycle to enable the ADC reading $\left(\mathrm{D}_{0}-\mathrm{D}_{7}\right)$ is executed through control bit $\left(\mathrm{P}_{3.7}\right)$. The input data from port $\left(\mathrm{P}_{0.0}-\mathrm{P}_{0.7}\right)$ stored in the address $(30 \mathrm{H})$ of the data memory as shall be explained in the ADC measurement cycle of the preceding paragraph.

(MPP) computation is also performed by this unit after the measurement of the open circuit voltage $\left(\mathrm{V}_{\mathrm{oc}}\right)$ of the $(\mathrm{PV})$ panel when it was disconnected from the load momentarily. The $\left(\mathrm{V}_{\mathrm{oc}}\right)$ value is stored in the address $(40 \mathrm{H})$ of the data memory.

The voltage $\left(\mathrm{V}_{\mathrm{mp}}\right)$ for maximum power is calculated by the following equation:

$\mathrm{V}_{\mathrm{mp}}=0.8 \mathrm{~V}_{\mathrm{oc}}$

This value is stored in the address $(41 \mathrm{H})$ of the data memory. The duty cycle of the PMW signal is also calculated in this unit and fed to the step down inverter through the output control bit $\left(\mathrm{P}_{2.7}\right)$. Computation of PWM is carried out by the following steps : 
The period $(\mathrm{T})$ is calculated from the following formula:

$\mathbf{T}=\mathbf{1} / \mathbf{f}_{\mathbf{c}}$

Where $f_{c}$ is the reference frequency in $\mathrm{KHz}$ and $(\mathrm{T})$ in microsecond. Hence the equation

(4) becomes:

$\mathbf{T}=\mathbf{1 0 0 0} / \mathbf{f}_{\mathrm{c}}$

and this value is stored in the address $(22 \mathrm{H})$ of the data memory.

The on time $\left(T_{o n}\right)$ of the PWM signal is calculated from this key point equation:

$\mathbf{T}_{\text {on }}=\left(\mathbf{1}-\left(\left(\mathbf{V}_{\text {in }}-\mathbf{V}_{\text {mp }}\right) / \mathbf{V}_{\text {in }}\right)\right) * \mathbf{T}$

which can be easily simplified to this formula:

$\mathbf{T}_{\mathrm{on}}=\left(\mathbf{V}_{\mathrm{mp}} / \mathbf{V}_{\text {in }}\right) * \mathbf{T}$

where $V_{\text {in }}, V_{m p}$ represents the instantaneous and maximum power voltages of the (PV) panel respectively. $\mathrm{T}_{\text {on }}$ is stored in the address $(50 \mathrm{H})$ of the data memory.

The off time $\left(\mathrm{T}_{\text {off }}\right)$ of the PWM signal is calculated from the formula:

$\mathbf{T}_{\text {off }}=\mathbf{T}-\mathbf{T}_{\text {on }}$

$\mathrm{T}_{\text {off }}$ is stored in the address $(51 \mathrm{H})$ of the data memory. Once the $\left(\mathrm{T}_{\text {on \& }} \mathrm{T}_{\text {off }}\right)$ have been calculated, the duty cycle of the PWM signal is known and used to control the switching circuit of the chopper for maximum power.

\section{Measurement Unit:}

The measurement unit of the solar panal voltage consists of an ADC type 0803 interfaced through the data bus $\left(\mathrm{D}_{0}-\mathrm{D}_{7}\right)$ with 8051 microcontroller with the input port $\left(\mathrm{P}_{0}\right)$ as shown in fig.(6).

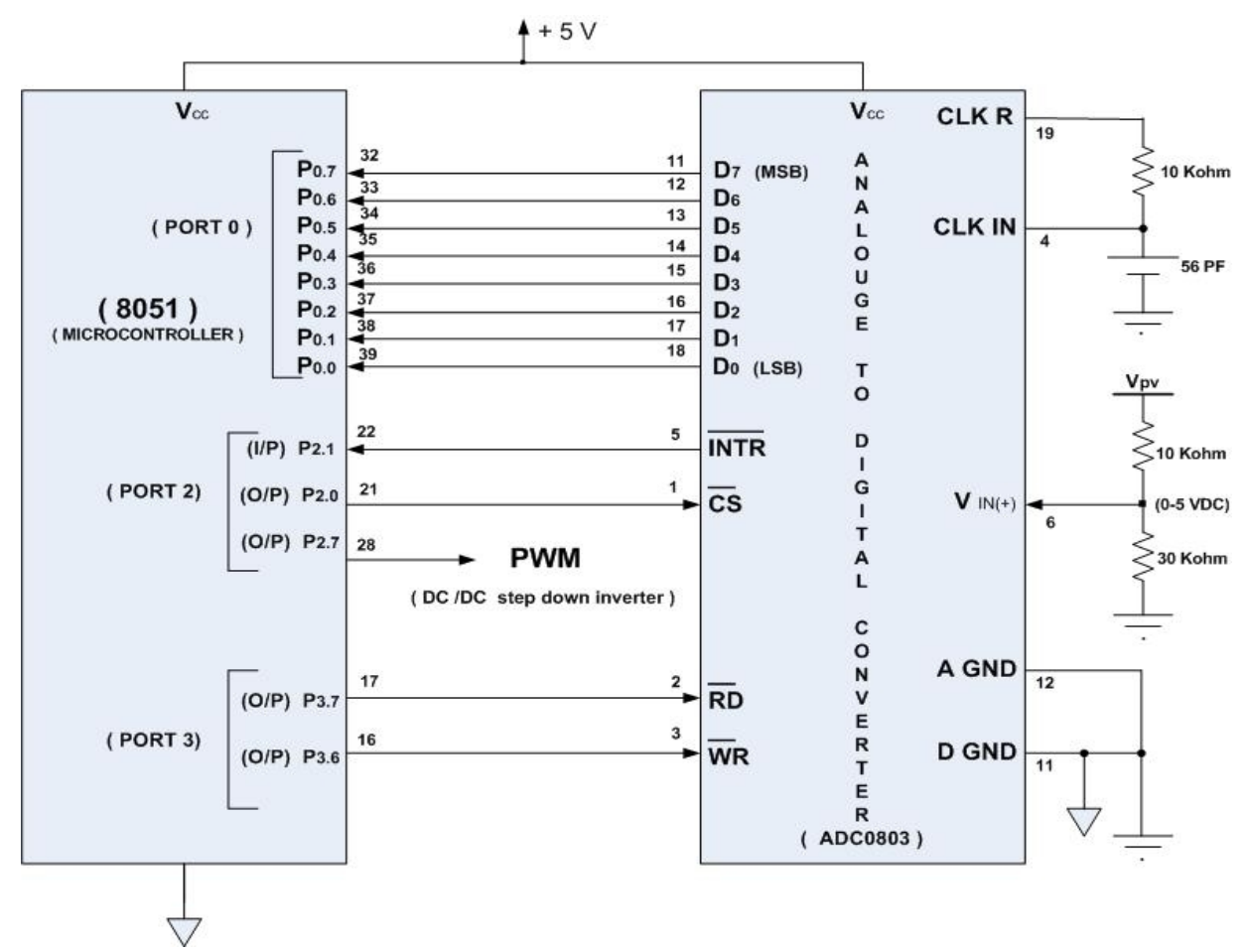

Fig. (6): Interfacing scheme of 8051 microcontroller to an ADC0803 
The measurement cycle shown in fig.(7) consists of three ADC readings. It is initiated by the 8051 through resetting the readings counter $\left(\mathrm{R}_{3}\right)$, defining the address buffer $(30$ $\mathrm{H})$ of the data memory and initialization of ADC control signals $(\overline{C S}=0, \overline{R D} \& \overline{W R}=1)$ are carried out. Then it will send start conversion pulse $(\overline{W R})$ to the $\mathrm{ADC}$ and waiting for the data to be ready thought the end conversion pulse $(\overline{I N T R})$ by testing the status bit $\left(\mathrm{P}_{2.1}\right)$ in a wait loop. After that, (8051) send read pulse to read the first value and store it into address $(30 \mathrm{H})$ of the data memory. Then it will increment $\left(\mathrm{R}_{3}\right)$ and buffer address by one and check if the three $\mathrm{ADC}$ readings are ended, if not it will go to the next reading and storing into successive location $(31 \mathrm{H})$ and continue until all readings are taken.

To increase the accuracy of the ADC readings voltage, the average value of three readings are calculated and stored in the address $(33 \mathrm{H})$ of the data memory.

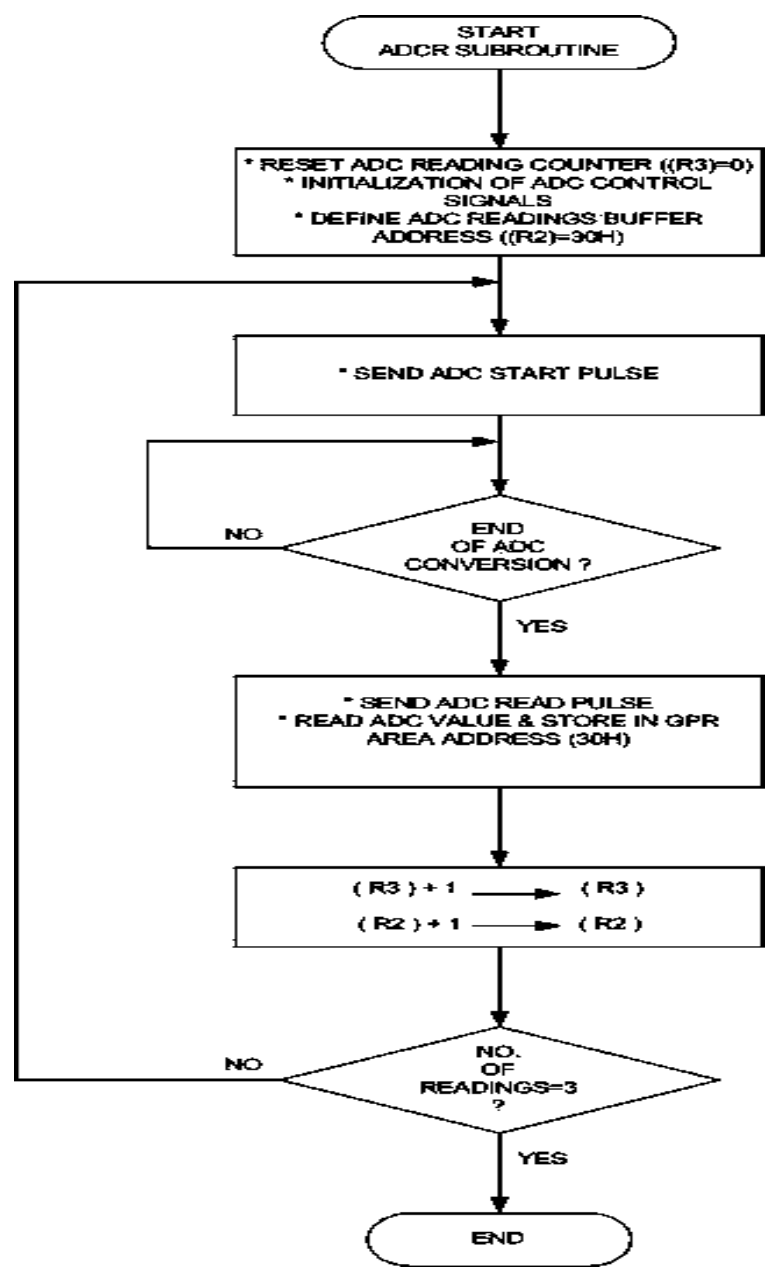

a : Flow chart

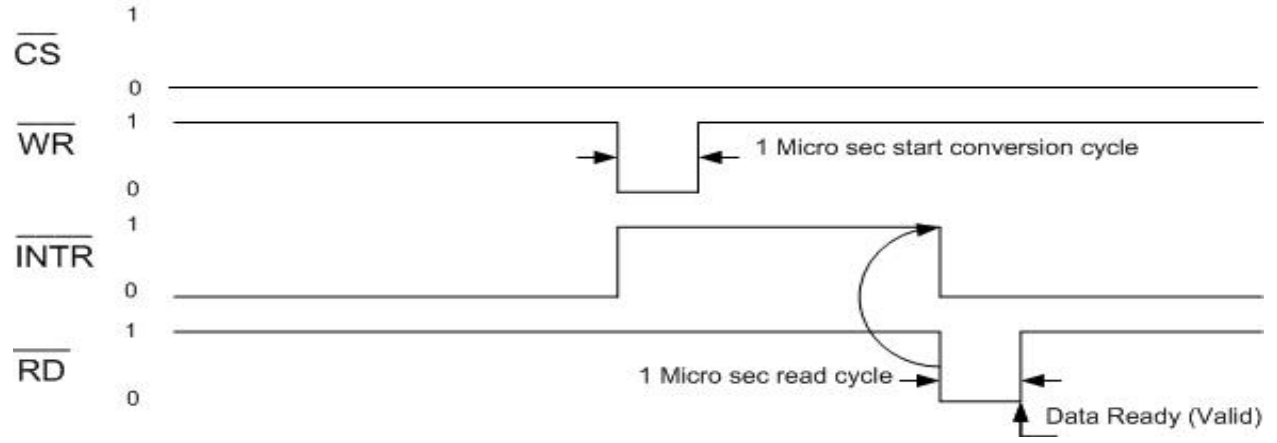

b : Timing diagram

Fig. (7) : ADC Measurement cycle: a- Flow chart b-Timing diagram

\section{Converter Unit:}

The converter unit consists of DC/DC step down converter (also called a chopper) applying switched-mode conversion which converts one DC voltage level to another, by storing the input energy temporarily and then releasing that energy to the output at a different voltage. This conversion method is more power efficient (often $75 \%$ to $98 \%$ ) than linear voltage regulation[14]. The output voltage from the step down converter shown in Fig.(4) are also simulated by OrCAD to optimize the selection of the LC filter. 


\section{The Main Control Program:}

The main task of this program is to perform the following steps:

1- Set the chopping frequency $\left(\mathrm{f}_{\mathrm{c}}\right)$, in the range $(4 \mathrm{KHz}-20 \mathrm{KHz})$ and storing it in address $(21 \mathrm{H})$.

2- Calculate the total period $(\mathrm{T})$ of the chopping signal which is equal to the total period of PWM signal.

3- Initialize the sampling periods: Two periods are suggested, the first one is the overall sampling period of $1 \mathrm{~min}$. (as shown in fig.(8)). This is to measure and compute $\mathrm{V}_{\mathrm{oc}}$ and storing in address $(40 \mathrm{H})$. The second sampling period of $1 \mathrm{~s}$ is to measure $\mathrm{V}_{\text {in }}$ and storing in address $(42 \mathrm{H})$. To control the scan of $1 \mathrm{~s}$ we initialize16-bit timer (TMR0) in $50 \mathrm{~ms}$ $(50000 \mu \mathrm{s})$ by taking the $2^{\prime}$ s complement of this count and loading it into (TH0 \& TL0) timer registers. (20) count steps stored in address $(61 \mathrm{H})$ as a down counter (R4) and decremented by one when (TMR0) get overflows for every $50 \mathrm{~ms}$ end. The $1 \mathrm{~min}$. time is controlled using (60) count steps stored in address $(60 \mathrm{H})$. It is also used as down counter (R5) and decremented every 1 s elapsed.

4- Measure and calculate $\mathrm{V}_{\mathrm{oc}}$ and $\mathrm{V}_{\mathrm{mp}}$ every $1 \mathrm{~min}$.

5- Measure and calculate $\mathrm{Vin}, \mathrm{T}_{\text {on }} \& \mathrm{~T}_{\text {off }}$ every $1 \mathrm{~s}$.

6-Generation of PWM signal using 16-bit timer (TMR1) with the above calculated $\mathrm{T}_{\text {on }} \&$ $\mathrm{T}_{\text {off. }}$

7- Check if $1 \mathrm{~s}$ period is ended, if not reinitialize (TMR0) and jump to regenerate PWM signal, if yes decrement (R5) then test if $1 \mathrm{~min}$. is finished, if not reinitialize counter (TMR0) and go to measure new $V_{\text {in }}$ (step5) and repeat the cycle, if yes indicates ending of overall period then will go to stpep1 in a continuous loop and so on. The detailed flow chart of this main control program is shown in fig.(9).

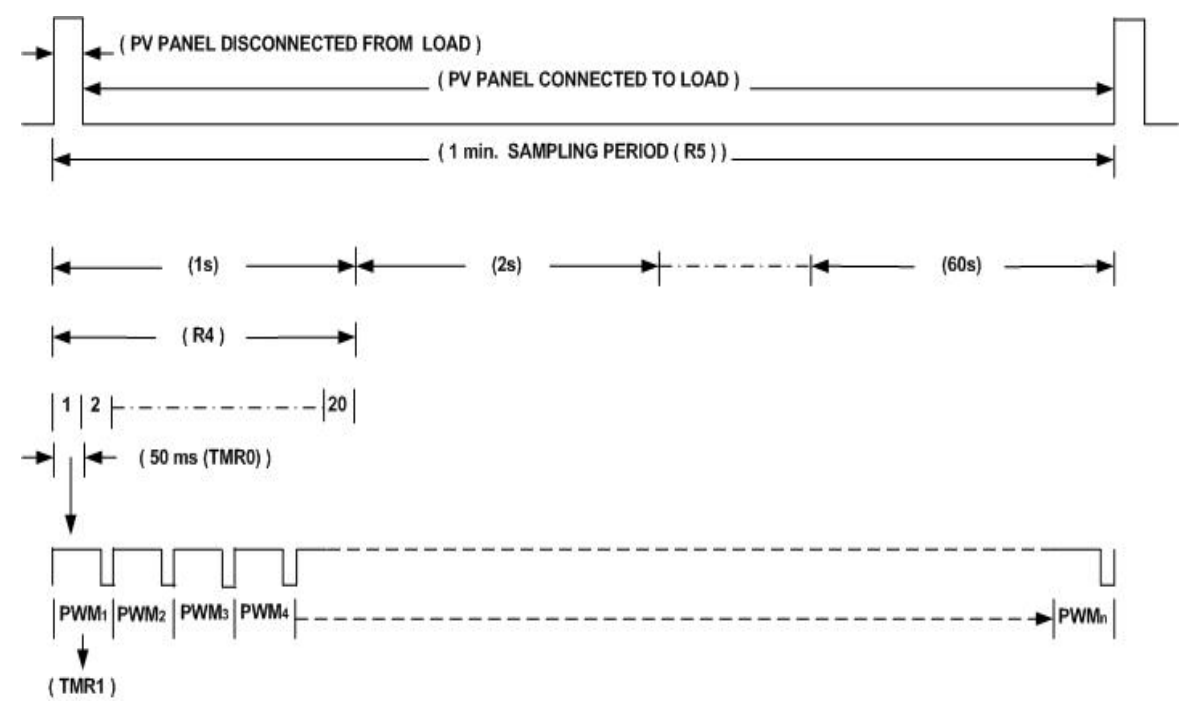

Fig. (8): Scanning of sampling periods

To overcome the shortage of division instruction of the microcontroller 8051 and make it handle the division of two byte by single byte, we use the method proposed by Morris Mano [15]. Equation (7) needs this type of division so we wrote a small program using the restoring method of double-byte, restoring method means that the partial remainder is restored by adding the divisor to the negative difference. 
Fig.(10) illustrates this method, at the end of the program the (Quotient) is stored in address $(24 \mathrm{H})$ while the (Remainder) is found in address $(25 \mathrm{H})$.

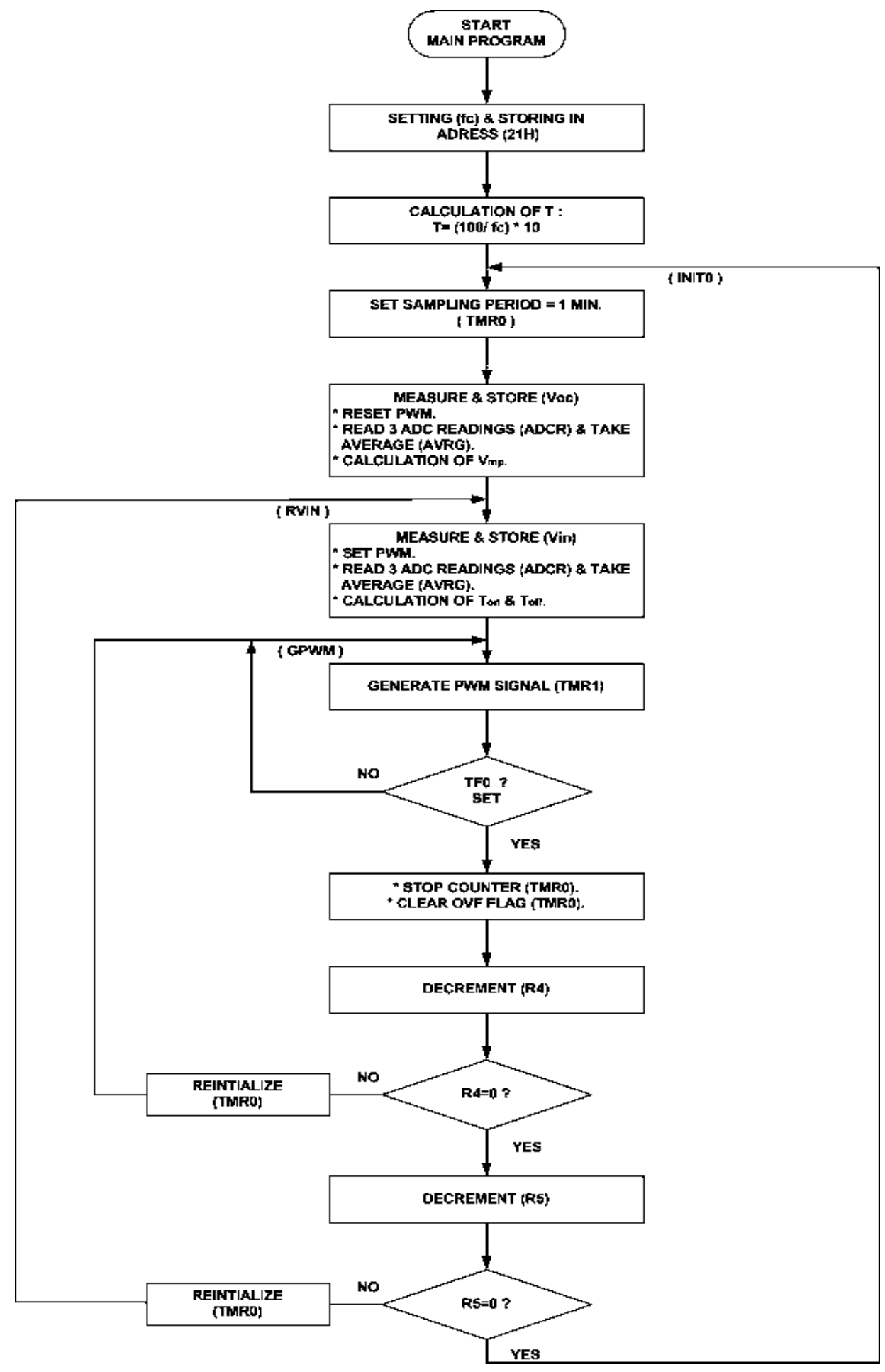

Fig. (9) : Detailed flow chart of the main control program 


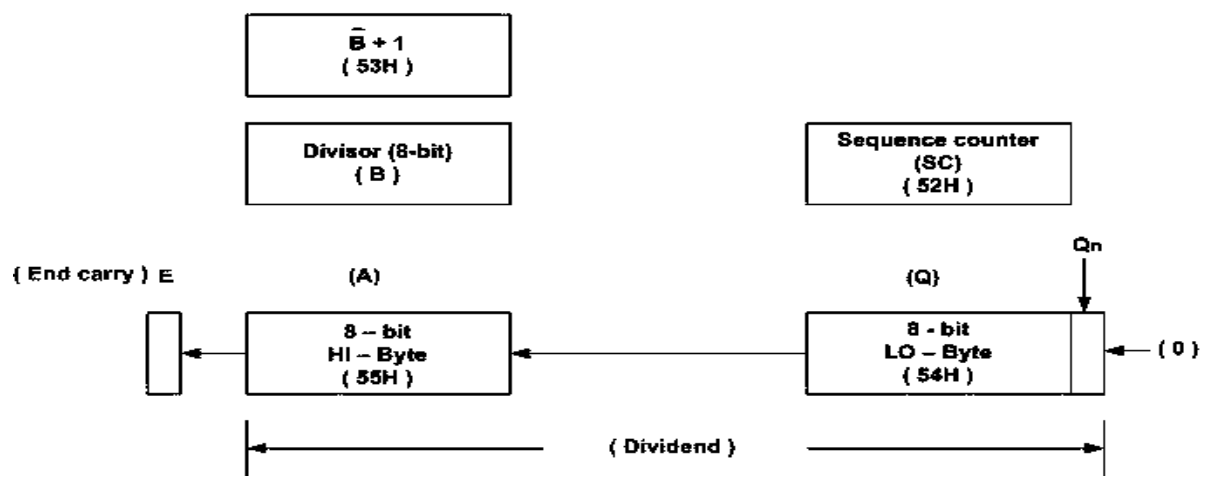

a- Hardware block

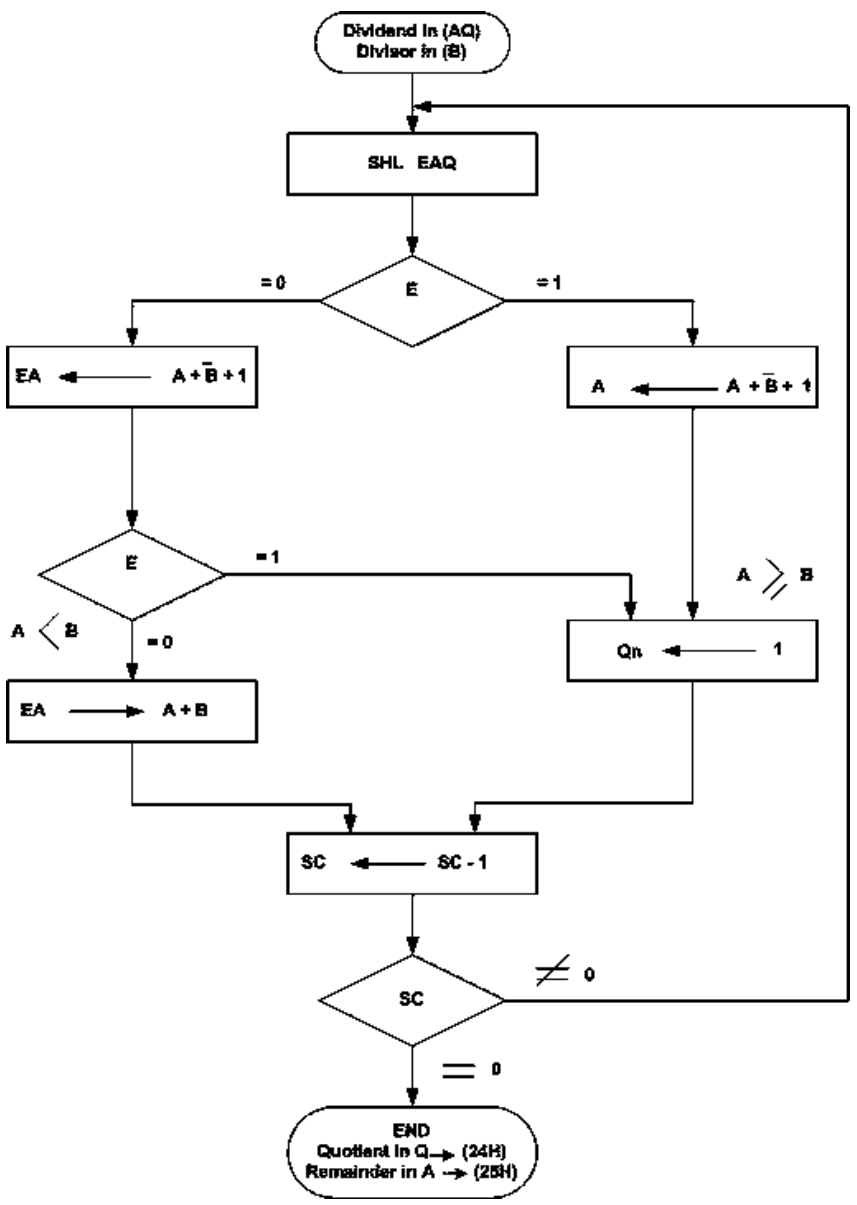

\section{b- Flow chart}

Fig. (10) : Double- byte division: a- Hardware block b- Flow chart 


\section{Experimental Result and Discussion}

The experimental setup to evaluate the performance of the MPPT algorithm consisted on Microcontroller Training System type MTS-51. The electronic circuit is controlled by an 8bit microcontroller 8051 from Microchip Technology where the MPPT algorithm and the optimal seeking algorithm have been programmed. The results shown in fig.(11) are the MPPT controlling PWM signals for three different cases $\left(V_{\text {in }}=20 v, 18 v \& 16 v\right)$ based on the real-time algorithm implemented in this low cost 8 bit microcontroller.

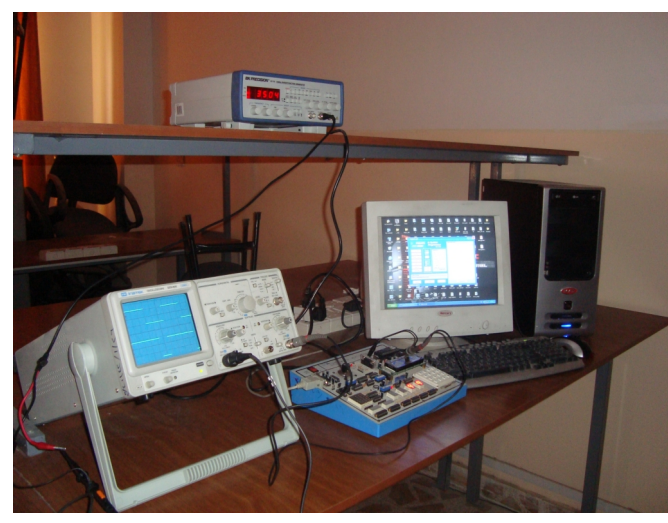

a- Microcontroller Training System (MTS-51)

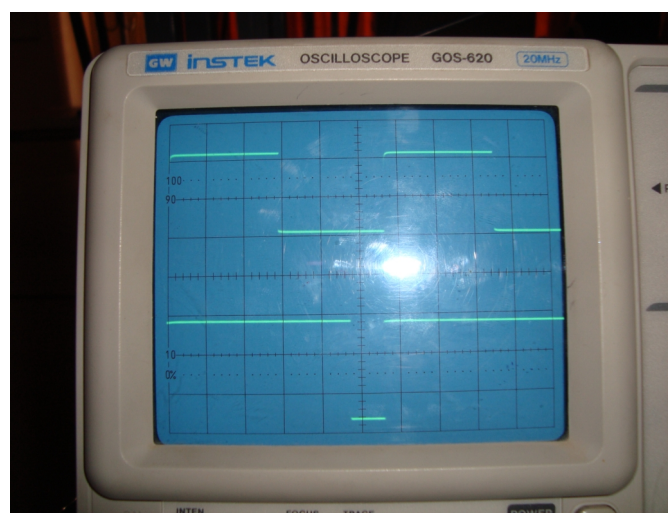

c- Reference and PWM signals

(2)

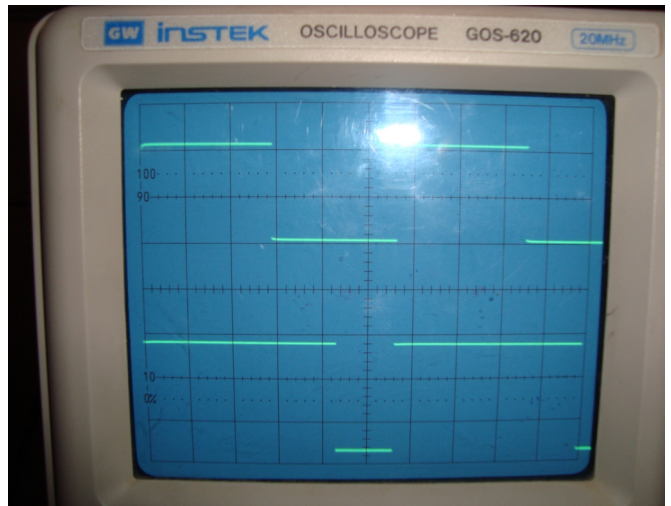

b- Reference and PWM signals

(1)

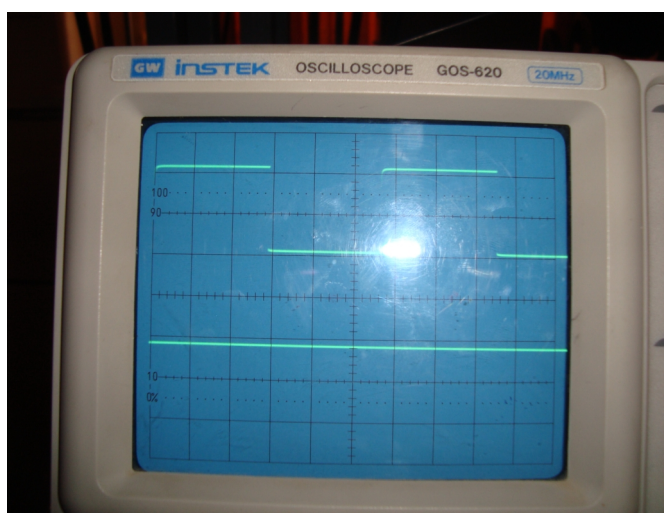

d- Reference and PWM signals

(3)

Fig. (11) : Experimental photos of Microcontroller Training System, Reference and PWM signals ( 3 cases)

To verify the circuit performance, we implemented computer- aided simulation using PSpice. In the simulation the assumptions made for the analysis same as given in other work [16] :

1. The Converter ( power transistor and diode ) are ideal switches.

2. The switching losses are neglected.

3. The passive components are linear and frequency independent.

The output voltage $V_{\text {out }}$ versus input voltage $V_{\text {in }}$ are obtained for a selected designed circuit of filter has the following specifications: $\mathrm{L}=1 \mathrm{mH}, \mathrm{C}=100 \mu \mathrm{F}$, and loaded system equivalent to $1.22 \mathrm{~A}$.

The results shown in fig.(12) are for three different input voltages and its relative PWM controlling signals and the output voltages and currents. 


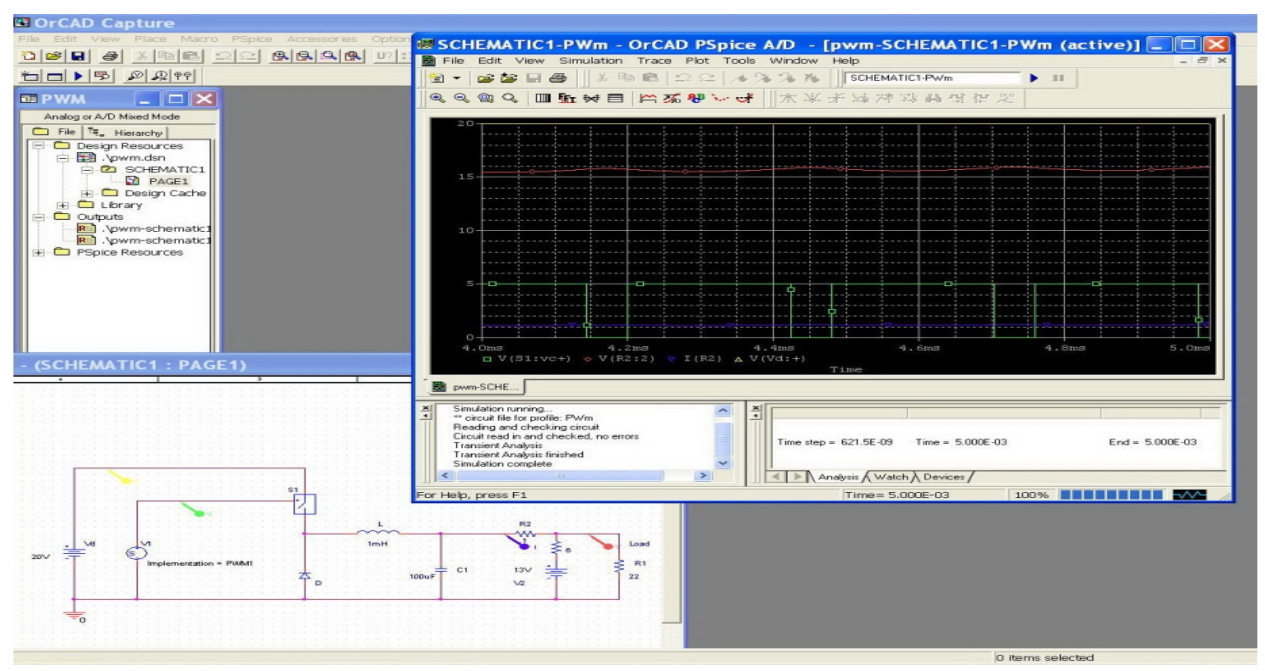

a- Vout and PWM signals for Vin=20v

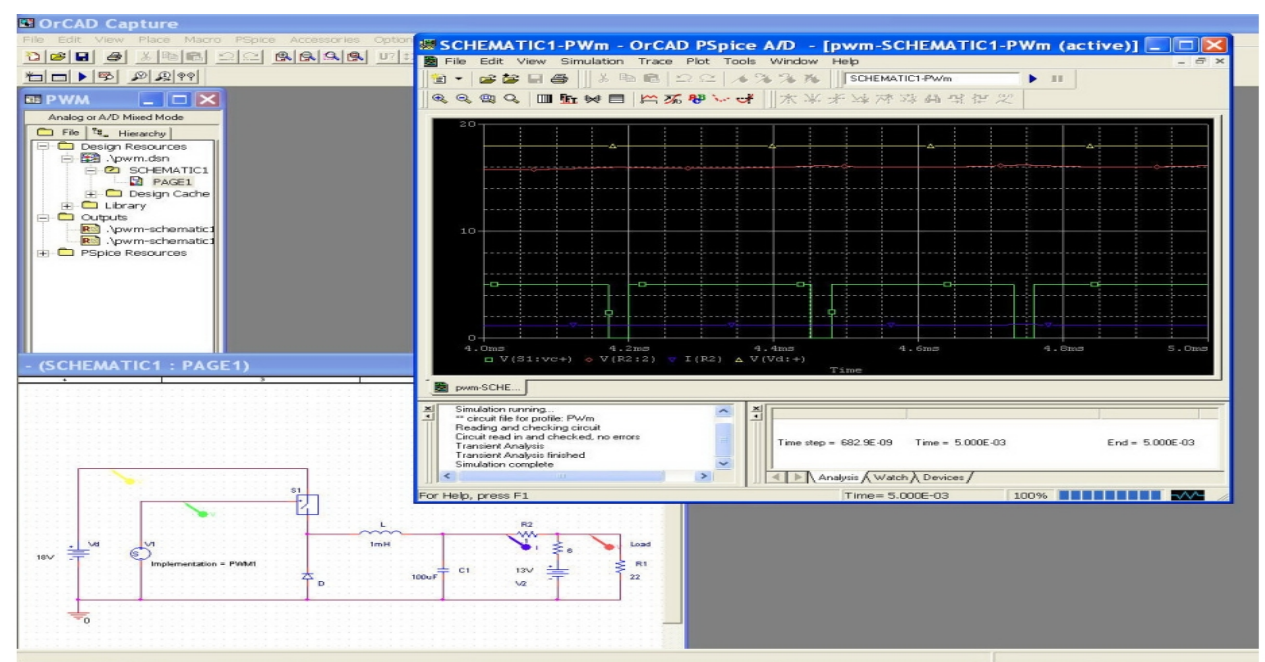

b- Vout and PWM signals for $\mathrm{Vin}=18 \mathrm{v}$

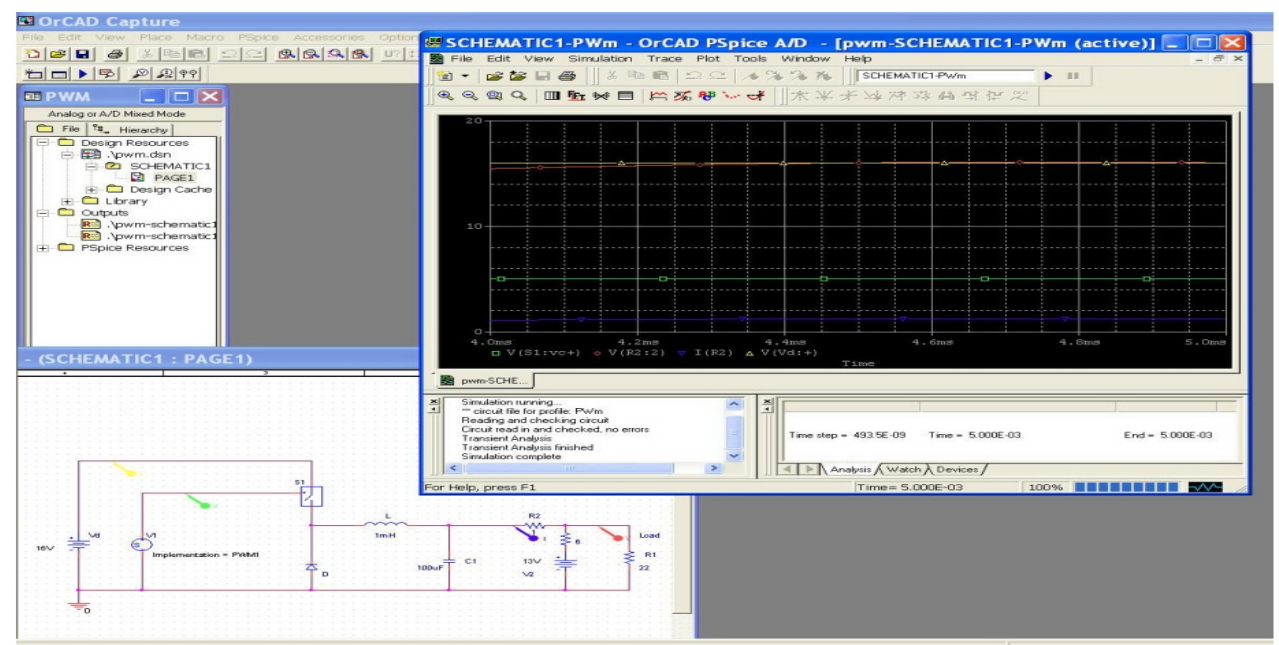

c- Vout and PWM signals for Vin=16v

Fig. (12) : Pspice simulator photos of Vout and PWM signals for different values of Vin 
Fig.(13) shows the practical PV panel V-I-P characteristic manufactured by AL-Mansoor Factory - Baghdad. It is obvious that this PV panel has maximum power around $20 \mathrm{~W}$ at $16.6 \mathrm{~V}$ and $1.22 \mathrm{~A}$ knowing that $\mathrm{Voc}=20.5 \mathrm{~V}$. This makes the assumption of taking the MPP voltage $\left(\mathrm{V}_{\mathrm{mp}}\right)$ around $(0.8 \times \mathrm{Voc})$ is substantial.

This means for battery loaded system it is obvious: without the MPPT, the PV panel would operate at a battery voltage of around $12 \mathrm{~V}$ to $14 \mathrm{~V}$, giving about $20 \%$ less power than when operating at the MPPT of $16.6 \mathrm{~V}$. And worse case happens if the battery was uncharged.

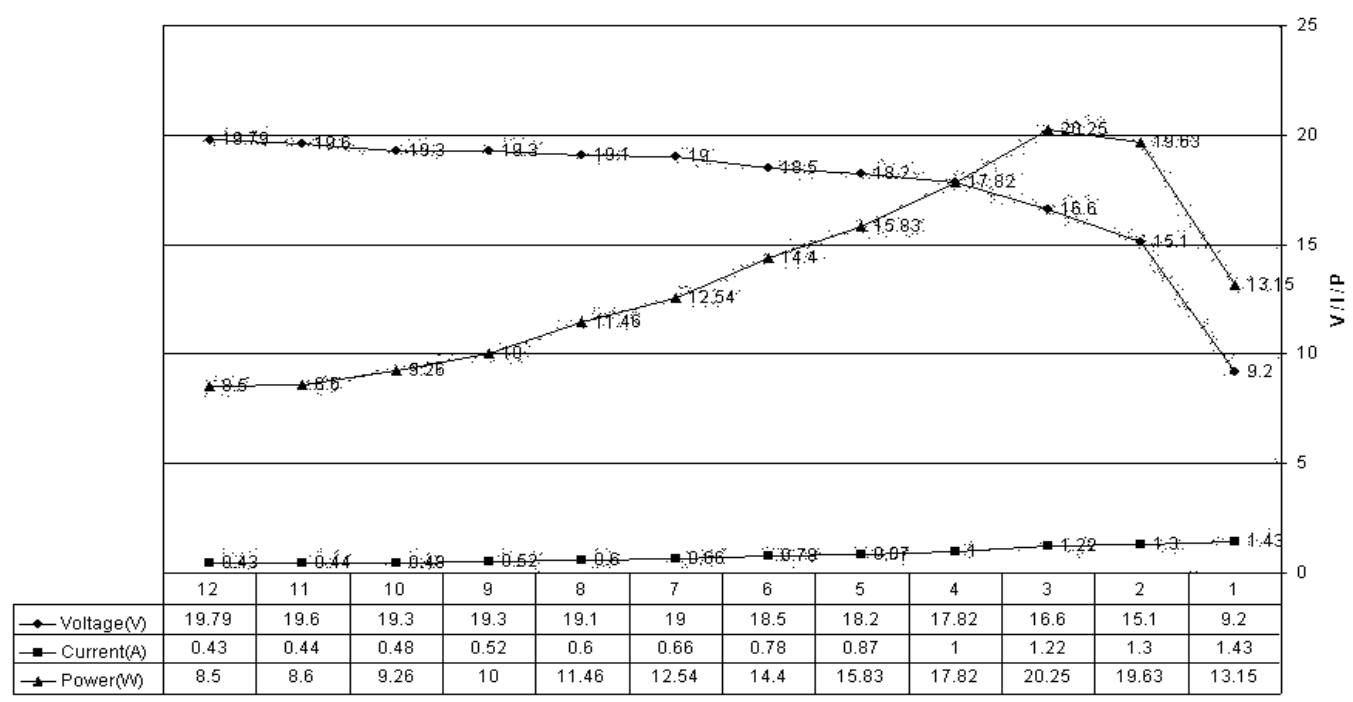

Fig. (13) : Practical V/ I / P characteristics of a solar PV panel

\section{Conclusion}

The objective of this work was to develop a solar array optimum power tracker that would be able to provide a load with maximum power. It was our desire to design a cheap and stand-alone microcontroller based solution system which can generate the required control PWM signal for the dc/dc converter. Also, this paper has described the application of MPPT through the reading of only PV panel open voltage to simplify the design. The practical results has been simulated and demonstrated on OrCAD ( PSpice ) simulator.

The PV panel is disconnected from the load momentarily and regularly to measure the open circuit voltage $V_{o c}$ which is stored and used for calculation of $V_{m p}$. The main drawback of this method is that the power delivered to the load falls to zero during the excuting time which is found $100 \mu \mathrm{s}$ ( Knowing that 8051 processor works at $1 \mathrm{MHz}$ ). This can be solved by using higher speed microcontroller.

\section{References}

[1] ARCO SOLAR, Installation Guide For $\mathrm{m} 25, \mathrm{~m} 55, \mathrm{~m} 65, \mathrm{~m} 75$ Solar Electric Modules, P.O. Box 2105 Chatsworth, CA 91313. doc.nr. 233-701500-20.

[2] Abu Tariq, M.S.Jamil Asgar, "Development of an Analog Maximum power point Tracker for Photovoltaic Panel", Dept. of Elect. Eng., Aligar Muslim University, Aligar 202002, India, IEEE PEDS 2005. 
[3] Bernard Bekker and H.J Beukes "Finding an optimum PV Panel maximum power point tracking ", IEEE AFRICON 2004.

[4] Mehmet Bode, Muammer Ermis, "Maximum power point tracking for low power photovoltaic solar panels", Electrical and Electronics Eng. Dept., Middle East Technical University, 06531, Ankara, Turkey, 1994 IEEE.

[5] H.D. Maheshappa, J.Nagaraju, and M.V. Krishna Murthy " An improved maximum power point tracker using step-up converter with current locked loop" Renewable Energy Conversion and Management, vol.13 , No.2, pp. 195-201, 1998.

[6] Nicola Femia, Giovanni Petrone, Giovanni Spagnuolo, and Massimo Vitelli, " Optimization of Perturb and Observe Maximum Power point tracking method", IEEE Trans. Power Electronics, vol. 20, No.4, pp. 963-973, July 2005.

[7] Khalid Khleel Mohamed, Amina Edrees Kanaan " A High Efficiency Max. power Point Tracking for Photovoltaic Arrays " Al-Rafidan Engineering Journal, vol.17, No.6, December 2009.

[8] Dezso Sera, Remus Teodorescu, Jochen Hantschel, and Michael Knoll "Optimized Maximum Power Point Tracker for Fast-Changing Environmental Conditions" IEEE tran. On Industrial Electronics, vol. 55, No. 7, July 2008

[9] K. Hardo, and G. Zhao, "Controlled power interface between solar cells and ac source " IEEE Trans. On Power Electronics, vol.8 , pp. 654-662, October 1993.

[10] Chian-Song Chiu "T-S Fuzzy Maximum Power Point Tracking Control of Solar Power Generation Systems" IEEE tran. Energy conversion, vol.25, No. 4, December 2010.

[11] M.A.S. Masoum, S.M. Mosavi, and E.F Fuchs, "Microprocessor-controlled new class of optimal battery charges for photovoltaic applications", IEEE Trans. On Energy conversion, vol.19, No.3, September 2004.

[12] G.W. Hart, H.M. Branz , C.H. Cox III , "Experimental Tests of open loop Maximum Power Point Tracking Techniques for Photovoltaic Arrays", Solar cells, vol.13 1984 pp. 185195.

[13] I. Scott Mackenzie "The 8051 Microcontroller" Prentice Hall, 3 rd Edition, 1999.

[14] Ned Mohan "Power Electronics :Converters, Applications \& Design" Wiley, 2002.

[15] M. Morris Mano "Computer System Architecture", California Stare University, Los Angeles , Prentice-Hall International, Third Edition.

[16] Nisha Das and Marian K. Kazimierczuk, "Power Losses and Efficiency of Buck PWM

DC-DC Converter", IEEE Proceedings, Electrical Insulation Conference and Electrical Manufacturing, Oct. 2005, pp. 417-423. 